\title{
O Estado e o Agro em tempos de liberalização*
}

\author{
Guilherme Leite da Silva Dias**
}

Resumo: Os conflitos decorrentes de crises de endividamento rural e aqueles oriundos da excessiva concentração da posse de terras vêm sendo canalizados para o Executivo Federal, sem a intermediação das agencias de crédito, das representações locais dos produtores e dos movimentos sociais. A representação política destes interesses no Congresso e junto ao Executivo cria um viés fundamental pela socialização dos custos e maior concentração dos benefícios.

Palavras-chave: política agrícola, crédito rural, reforma agrária, federalização, concentração.

Classificação JEL: Q 10, Q 13 e Q 15.

Abstract: Conflicts following from rural credit indebt ness and excessive concentration of land ownership have been dealt by the central executive office without the intermediation of local farmers organization and social movements. The political representation of these interests in Congress and close to the Executive bare a fundamental bias toward cost socialization and further concentration of benefits.

* Aula Magna do Professor Guilherme Leite da Silva Dias apresentada no XLIV Congresso da Sociedade Brasileira de Economia e Sociologia Rural - SOBER, em 23/07/2006 em Fortaleza, CE.

** O autor é Professor Titular da Faculdade de Economia, Administração e Contabilidade da Universidade de São Paulo, E-mail: guildias@usp.br. 
Key words: agricultural policy, rural credit, agrarian reform, federalism, concentration.

JEL Classification: Q 10, Q 13 e Q 15.

\section{Introdução}

O objetivo perseguido nesta palestra é de esclarecer a relação do Estado com o setor agropecuário nestes tempos de liberalização da economia brasileira. Faremos isto pela experiência mais recente do nosso desenvolvimento agrícola, especialmente das sucessivas intervenções públicas no mercado de crédito rural e na estrutura fundiária;

$\mathrm{Na}$ literatura recente sobre desenvolvimento econômico aparecem referencias recorrentes ao papel das instituições políticas na resolução dos conflitos sociais, definindo o grau de cooperação no momento seguinte entre os principais grupos de interesse econômico responsáveis pela oferta de bens coletivos (Acemoglu et alii, 2004; Aguirre, 2006).

A cooperação é fundamental para a redução dos custos de transação decorrentes da assimetria de informação entre credores e agentes de credito, assim como para a conformidade com critérios de racionamento impostos pela autoridade pública. Também o é na questão do exercício dos direitos de propriedade sobre a terra, onde além da presença de uma pletora de externalidades (a preservação do meio ambiente é apenas uma delas) temos o problema da legitimidade da concessão original, ou seja, o reconhecimento do poder de fato do Estado definir $\mathrm{o}$ acesso à terra comum.

\section{Os conflitos recentes de inadimplência no credito rural}

De 1985 até hoje passamos por três graves crises de adimplência nos contratos de crédito rural; o primeiro no ano agrícola 1986/1987, o segundo começou em 1991/1992 e foi se arrastando até 1999, o terceiro começou em 2004/2005 e segue seu curso até agora. O primeiro foi resolvido no estilo da época, a taxa nominal fixa de juros de 10 por cento ao ano foi prorrogada por seis meses quando o país mergulhava na hiperinflação (pós-fracasso do Plano Cruzado). O saldo devedor de- 
sapareceu como por milagre, o Banco do Brasil não faliu porque continuava com o poder de emissão de moeda na "conta movimento", o nível dos empréstimos em relação ao PIB rural é que nunca mais voltou aos mesmos valores.

Estávamos então nos anos da crise do Estado Autoritário, era o esgotamento da capacidade autônoma do Estado de promover grandes transferências de renda sem o controle político da sociedade. A legitimidade do Estado para intervir no domínio econômico ficou comprometida, o Congresso Constituinte de 1986/1988 é uma tentativa de recuperar e limitar o poder de um Estado Democrático. Esta transição está cheia de conflitos que se manifestam no SNCR (sistema nacional de credito rural) pela introdução dos mecanismos de indexação monetária e de uma taxa real de juros elevada que compromete tanto o seu papel de crédito dirigido como de instrumento eficaz da política agrícola e, mais importante ainda, de mecanismo legítimo de racionamento. Os produtores que não anteciparam as implicações das mudanças entram em graves crises de inadimplência, os "agentes" do sistema de crédito, principalmente bancos federais e estaduais, vão desenvolver mecanismos de rejeição à formação de um novo mercado competitivo de crédito, como qualquer outro grupo de interesse organizado. O quadro é agravado mais ainda pelos sucessivos fracassos dos planos heterodoxos de controle da hiperinflação, quando os indicadores oficiais de indexação monetária dos contratos de credito rural sofrem variações incompatíveis com o comportamento dos preços dos produtos agrícolas determinados por mercados mais competitivos.

Os bancos, diante da oportunidade de transferir parte do custo da inadimplência para o Estado, realizam uma série de operações com o propósito de omitir informações detalhadas sobre o nível de inadimplência dos devedores rurais. Isto foi feito por concessão de novas operações para liquidar saldos inadimplentes ("mata-mata") e também para a liquidação de operações de credito geral ou pessoal ("hot-money") que originalmente fugiam aos padrões do SNCR e, portanto, não eram financiadas com recursos da exigibilidade (financiamento compulsório com uma porcentagem dos depósitos a vista). Ao mesmo tempo, estão elevando o valor dos seus ativos buscando a realização desta renda no Estado pela troca dos contratos de dívida dos agricultores por títulos 
de dívida pública, liberando seu valor do risco da inadimplência dos devedores rurais.

O agente de credito, a organização bancária e o gerente operador da carteira, vão desenvolver métodos alternativos de captação de parte do beneficio transferido (o subsídio na taxa de juros) para o agricultor tomador do credito; estas operações, conhecidas como reciprocidades, vão se constituir num caso típico de distorção "do agente/principal" (Hoff, Braverman e Stiglitz; 1993). O principal neste caso é o governo, que vê limitada a sua capacidade de controle sobre a operação do sistema de crédito; o agente neste caso é o banco estatal (o Banco do Brasil principalmente) que faz predominar seus próprios objetivos sobre os do principal, como um grupo de interesse privado qualquer. A percepção pelos agentes de crédito de um excessivo nível de endividamento do setor produtivo, não tinha capacidade de inibir o volume total de recursos aplicados.

Os produtores, por sua vez, também organizam um grupo de interesse eficiente a partir da formação da CPI do crédito rural (Comissão Parlamentar de Inquérito em 1993-1994), quando passam a serem coordenados pela bancada ruralista no Congresso. Todo o processo de reconstrução de um novo mercado de crédito rural ficou comprometido por esta estratégia de defesa dos interesses tradicionalmente privilegiados pelo SNCR. O Estado continua envolvido e ator central, mas agora sem os instrumentos eficientes de controle e planejamento do passado.

Diante da segunda crise de inadimplência em 1995, o Governo Federal, sob a pressão da Bancada Ruralista, foi obrigado a promover renegociações sucessivas do seu saldo vencido, com aumentos progressivos de subsídios na forma de renúncia de parte destes valores. A grande diferença está no controle social sobre as contas públicas, o orçamento público não é mais uma ficção e os números podem ser analisados. 
Gráfico 1- Despesa Orçamentária

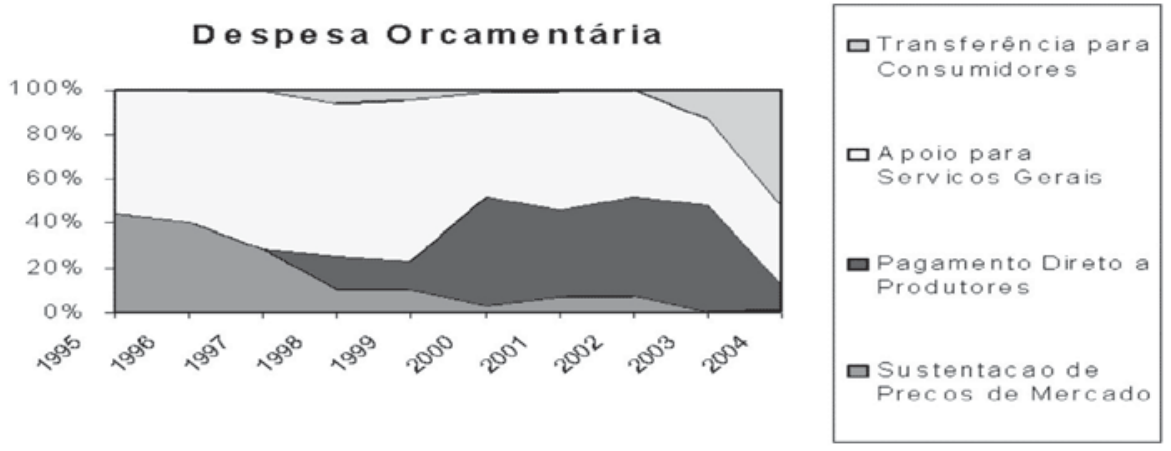

Fonte: OECD, 2005

O Gráfico 1 acima, com dados do relatório da OECD sobre política agrícola no Brasil, indica uma grande mudança na composição das despesas orçamentárias, com redução nos gastos de sustentação de preços mínimos, também no apoio para serviços gerais, com aumento intermediário para os pagamentos diretos a produtores (prêmio de escoamento da produção-PEP) e sua posterior redução com o aumento das transferências para os consumidores (Fome-Zero depois Bolsa-Família).

No Gráfico 2 podemos ir além com a abertura dos pagamentos a produtores, onde os gastos com a reestruturação da dívida bancária tomou a lugar da equalização de preços depois de 2000.

Gráfico 2 - Transferência Direta para Produtores

\section{Transferência Direta para Produtores}

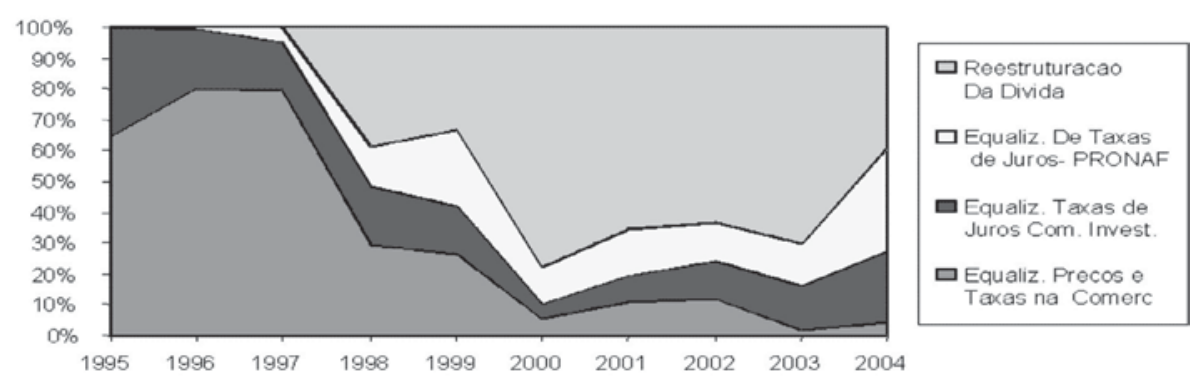

Fonte: OECD, 2005. 
No Quadro 1 abaixo, verificamos que de uma despesa geral de 13 bilhões de reais, 11 foram para os bancos, pouco menos de um bilhão foi rebate para os produtores, os quais já tinham pagado até o final de 2004 pouco mais de dois bilhões.

Quadro 1 - Despesas Orçamentárias

\begin{tabular}{|c|c|c|c|}
\hline \multicolumn{4}{|c|}{ Fluxo das Despesas Orçamentárias (1998-2004) } \\
\hline Agente & Valor & $\%$ & Operação \\
\hline Bancos & 4.944 .763 & $46 \%$ & Securitizacao Divida (Lei 9138/95) (I) \\
\hline Bancos & 6.563 .041 & $61 \%$ & Apoio a Divida Interna do Setor Agrícola \\
\hline Bancos & 371.383 & $3 \%$ & Prog. Equaliz para Grandes Devedores - PESA (Lei 9866/99) (J) \\
\hline Produtores & 969.500 & $9 \%$ & Rebate Taxa de Juros (5\%) no PESA (Lei 9866/99) (L) \\
\hline Bancos & 47.716 & $0 \%$ & Securitizacao Divida no BNDES (L $9138 / 95$ e $9866 / 99$ ) \\
\hline Produtores & 1.595 .036 & $-15 \%$ & Pagamento dos Pequenos e Médios Devedores (Lei 9138/95) \\
\hline Produtores & 518.831 & $-5 \%$ & Pagamento dos Grandes Devedores - PESA (Lei 9866/99) (J) \\
\hline
\end{tabular}

Fonte: OECD, 2005.

Se existe uma política oficial refletida no balanço destes dados, vale a pergunta sobre quais são as prioridades reveladas por estes números?

Os bancos em geral já foram compensados, o Banco do Brasil transferiu a carteira e todo o risco para o Tesouro, portanto, estão livres do problema. Os produtores estavam mantendo uma elevada inadimplência sobre o reescalonamento das dívidas; parecem estar querendo um desconto maior ainda do que já tinha sido concedido em 2001. O Tesouro ficou com uma carteira vinda do BB com elevada inadimplência. O resto da sociedade vai provavelmente pagar dobrado pelo beneficio já transferido para aqueles dois grupos nos 24 anos da prorrogação (Silva, Grossi e Porto, 2006).

\section{Os conflitos fundiários e da base legal herdada}

Num país com amplas fronteiras agrícolas, o mercado de terras apresenta uma estrutura peculiar porque a oferta de terras depende da política do Estado para a incorporação gradual das terras públicas ao patrimônio do setor privado. Isto se faz pela geração de dois bens coletivos: de um lado a legislação fundiária fornece os estímulos e as restrições ao domínio privado, de outro os investimentos em infraestrutura de transporte geram reduções no custo do transporte integrando a fronteira ao mercado (Dias, 1978). 
Onde o Estado exerce uma "política fundiária ativa", ele assume a ação de identificar as terras públicas disponíveis e vai colocá-las à disposição dos produtores pela venda ou por transferência de direitos de uso, determinando a configuração futura da estrutura agrária. A outra que chamaremos de "passiva", o Estado corre atrás daqueles que ocupam terras públicas ou de domínio duvidoso através de processos de legitimação de posse (regularização fundiária, tanto administrativa quanto judicial). Onde existem situações de conflito aberto ou potencial, o Estado também corre atrás com a reforma agrária. Este Estado "passivo" é que foi decisivo para a nossa atual estrutura fundiária.

O preço de oferta e a quantidade de terras apropriadas (fronteira externa) pelo setor privado podem ter um efeito depressivo sobre o preço das terras anteriormente incorporadas ao domínio privado, mas que ainda não estão sendo utilizadas plenamente (fronteira interna). Este efeito depressivo será maior se o custo do transporte a partir da fronteira externa for muito baixo ou muito subsidiado pelo Estado (Dias, Vieira e Amaral, 2003). No caso clássico da fronteira oeste dos Estados Unidos, o governo doava lotes pequenos aos colonos que ocupassem a região (preço zero na fronteira) e a quantidade de colonos migrando determinava a quantidade de terras incorporadas ao domínio privado. A renda diferencial obtida na fronteira interna determinava o preço destas terras.

Se o domínio das terras de fronteira é permitido em antecipação aos investimentos em infra-estrutura de transporte, ocorre uma situação muito diferente, onde a abertura desta fronteira será determinada de acordo com a expectativa de realização de ganhos de capital. Neste cenário surge uma demanda "de reserva" destas terras pelo proprietário, derivada de um calculo sobre a probabilidade de valorização deste ativo. O horizonte de tempo deste calculo será maior se a concentração da posse destas terras for elevada e o preço "de reserva” (aquele pelo qual o proprietário/especulador vai começar a vender) será mais elevado se este mesmo proprietário também for dono de grandes glebas nas áreas já incorporadas ao processo produtivo. Estas são as características relevantes do nosso sistema de ocupação da fronteira agrícola por latifúndios em contraste com o sistema de colonização.

É a política "passiva” do Estado que mais contribuiu para o elevado nível de concentração da posse de terras. A legislação fundiária estimulava 
a ocupação com as facilidades oferecidas para a regularização de sua posse assim como pela ausência efetiva de limites ao tamanho da posse.

A oligarquia fundiária não retirava seu poder do controle sobre um fator escasso como a terra, como na Europa ou na China, mas fundamentalmente de sua estreita relação com o poder colonial e depois imperial, que lhes transferia poderes de Estado em troca do serviço de expandir e garantir o domínio territorial (Cirne Lima, 1954).

Estas terras de fronteira são conhecidas como "devolutas", conceito que revela um juízo de valor predominante na formação de nossa estrutura fundiária; o status jurídico "devoluta” implica um processo administrativo onde o Estado tem de provar diante do sistema judiciário que a terra não esta ocupada. Neste processo administrativo, "sinais de ocupação" bastam para identificar o domínio da terra por alguma pessoa que, portanto, pode reclamar a sua propriedade (Dias, 1978). O princípio básico favorecido por esta determinação é o do direito de ocupação das terras da nação, como na época inicial da colonização portuguesa. Não se estabelece limite para este direito de ocupação das terras pelo indivíduo, mas o Estado está limitado na sua capacidade de intervir porque ele precisa provar, diante da Justiça, que não existem "sinais de ocupação".

Neste processo as autoridades estaduais e os juizes das comarcas são os atores principais. Os primeiros porque podem decidir sobre a forma de vender as terras devolutas e resolver qualquer conflito sobre a posse de um lote, oferecendo a uma das partes envolvidas um lote alternativo das terras devolutas. Os juízes de comarca porque tinham o poder de reconhecer os "sinais de ocupação" que garantiriam o domínio privado sobre as terras. Nossa concentração fundiária é fruto deste processo histórico em que os conflitos eram resolvidos ao nível das autoridades locais.

É apenas em 1946 que aparece uma mudança importante (DecretoLei 9.760) com as normas para o processo de "Discriminação de Terras Devolutas", criando um organismo na área administrativa federal para dirimir os conflitos. Este movimento de centralização é o que perdura até hoje. Neste mesmo decreto, ainda mantendo a tradição de legitimar posses, admite-se a forma de incorporar terra devoluta ao domínio privado por "posse pacífica e ininterrupta, por trinta anos, independentemente de justo título e boa fé” (Junqueira, 1976; Mendonça Lima, 1977). 
Terão de passar quase 20 anos para aparecer nos textos legais uma diretriz clara de política fundiária ativa. Em 1964, aparece o "Estatuto da Terra” (Lei 4.505), fixando alguns princípios renovadores como a desapropriação por interesse social, seu pagamento com títulos especiais de Dívida Pública, condiciona o acesso à propriedade a sua função social. Os imóveis rurais são classificados em: propriedade familiar, minifúndio, empresa rural, latifúndio por dimensão e latifúndio por exploração; utilizando, portanto, de uma característica de tamanho e outra de destinação, a função social da terra.

É através de uma aceleração do processo de alienação, durante a década de 1970, que veremos, pela primeira vez na história de nossa política fundiária, as ações "ativas" do Estado (tanto central como estaduais) superarem as ações "passivas", transferindo para o domínio privado mais de 60 milhões de hectares. Foram assentados milhares de famílias em projetos oficiais de colonização, no entanto a esmagadora maioria das terras foi para projetos privados de colonização (até 500.000 ha) em glebas individuais que podiam ir de 3.000 ha até 60.000 ha. A concentração fundiária se acelerou com este padrão de ações ativas do poder público. Quando o Estado adicionou um programa de investimentos em infra-estrutura de transportes, promoveu o maior ganho especulativo com a posse de terras de nossa história, numa nítida ação de cooptação dos antigos donos de terras e dos novos empresários rurais ao "lento, seguro e firme" processo de transição para a democracia promovida pelo regime militar.

De lá para os tempos atuais foi a mudança na base técnica da produção agropecuária - com elevados ganhos de produtividade do trabalho (promovendo a expulsão e o desemprego de parcela expressiva da população rural), da terra (discriminando a terra menos produtiva em relação àquela de maior aptidão, discriminando as regiões de clima mais desfavorável) e dos insumos modernos produzidos pela indústria - que alterou o equilíbrio político anterior, introduzindo as empresas agroindustriais, os empresários rurais e uma massa de trabalhadores rurais semi-urbanizados como novos atores.

Muitos fatores convergiram para produzir mudanças na política ativa do Estado nos anos 80 e 90. Os movimentos sociais ganham expressão por maior adesão da população e melhor organização de suas agendas 
depois da fase repressiva do regime militar; crescem os conflitos na área rural entre os "sem terra" (trabalhadores rurais desempregados, arrendatários falidos, parceiros e moradores expulsos) e os donos de terras. Os primeiros movimentos organizados pela reforma agrária surgem neste contexto de esgotamento da fronteira agrícola nos Estados de Pernambuco, Rio de Janeiro e Rio Grande do Sul (Navarro, 1997). Nos outros Estados, onde a atividade agrícola era importante, a emigração para as novas fronteiras ainda existentes funcionava como válvula de escape, assim como a migração para as cidades. Entre as duas grandes secas no Nordeste, de 1981 e 1983, os movimentos sociais, sobre a liderança da Igreja Católica, começam a questionar a migração para as fronteiras agrícolas como uma medida paliativa inaceitável, porque a manutenção da exclusão social nas regiões de origem do emigrante era o caminho para a sua reprodução, com o devido tempo, na nova fronteira.

Como o poder normativo estava no Congresso e o Poder Executivo Federal, por sua vez, era visto pelas forças de esquerda como a forma mais adequada de conduzir um processo de revolução social de "cima para baixo", a luta política pela reforma agrária convergiu para concentrar, no executivo federal, o poder de desapropriar terras e de conduzir o processo de assentamento (Dias, 1997).

Os militares, depois da revolução de 1964, também haviam optado pela política fundiária ativa na esfera federal por razões de segurança nacional (no contexto da guerra fria) e estratégia de desenvolvimento econômico (concentração e aumento de poupança doméstica), consolidando o governo federal como principal ator e interlocutor do processo de reforma agrária. Grandes donos de terras e os grandes grupos econômicos também viam nesta centralização um elemento de defesa de seus interesses porque o dialogo era com um único interlocutor, o Governo Federal através da burocracia do INCRA e sua expressiva representação no Congresso, em especial do Senado, onde ficava o poder de controlar o executivo.

A Constituição de 1988, depois de um de seus episódios mais árduos e longos de debate, manteve o direito de expropriação de terra para fins de reforma agrária exclusivamente no Governo Federal. Repetiu-se o mesmo quadro político, conservadores confiantes na sua representação mais forte no Congresso, com poderes de neutralizar qualquer ação mais independente do Executivo Federal, e as esquerdas ainda acreditavam 
que qualquer ação revolucionária em favor da reforma agrária viria do governo central apoiado por forças populares (Ribeiro, 1987).

A resposta ao conflito social, estritamente pela reforma agrária no final dos anos 1980, levou as autoridades federais a suspender um tipo de ação eminentemente "ativa" de política fundiária, as ações discriminatórias. Elas estão previstas no Decreto-Lei 9.760/46 e nas Leis $3.081 / 56$ e 6.383 de 1976 , e permitiam aos governos federal e estadual conduzir uma ação administrativa, dentro de um perímetro geográfico, na qual todos os proprietários de imóveis rurais deveriam apresentar seus documentos de propriedade, para reconhecimento de seu valor legal e para a identificação de suas fronteiras com seus vizinhos. O levantamento topográfico faria o reconhecimento das coincidências e divergências, que poderiam ser convalidadas e/ou retificadas nos registros de Cartório de Imóveis. A área não coberta por títulos reconhecidos seria arrecadada pela União ou Estados como terra devoluta sendo que os posseiros, devidamente reconhecidos na mesma ação discriminatória, tinham prioridade de direito de assentamento, até o limite do módulo rural da região.

A dificuldade operacional deste procedimento está na exigência de um quadro de funcionários devidamente capacitado e no fato de que os levantamentos topográficos tradicionais eram morosos, caros e imprecisos, o que enseja recursos e contestações judiciais. A tecnologia moderna de geo-processamento por satélite contorna grande parte destes problemas. Quando existia uma situação prévia de conflito social na área identificada, era comum também a falta de segurança para o pleno desempenho das funções requeridas. O Gráfico 3 abaixo não deixa dúvida, no entanto, de que o processo podia ser conduzido com razoável eficiência, permitindo, entre 1977 e 1985, discriminar mais de 80,8 milhões de hectares e arrecadar mais de 110,4 milhões hectares. Estes dados se referem apenas às ações da União por falta de dados sobre a ação conduzida ao nível dos estados. A maioria destas terras foi licitada na forma descrita anteriormente, contribuindo para manter a concentração fundiária nos padrões históricos, o equívoco estava na forma de licitação destas terras e não na irrelevância das ações discriminatórias como instrumento de correção de estrutura fundiária. 
Gráfico 3 - Discriminação e Arrecadação de Terras

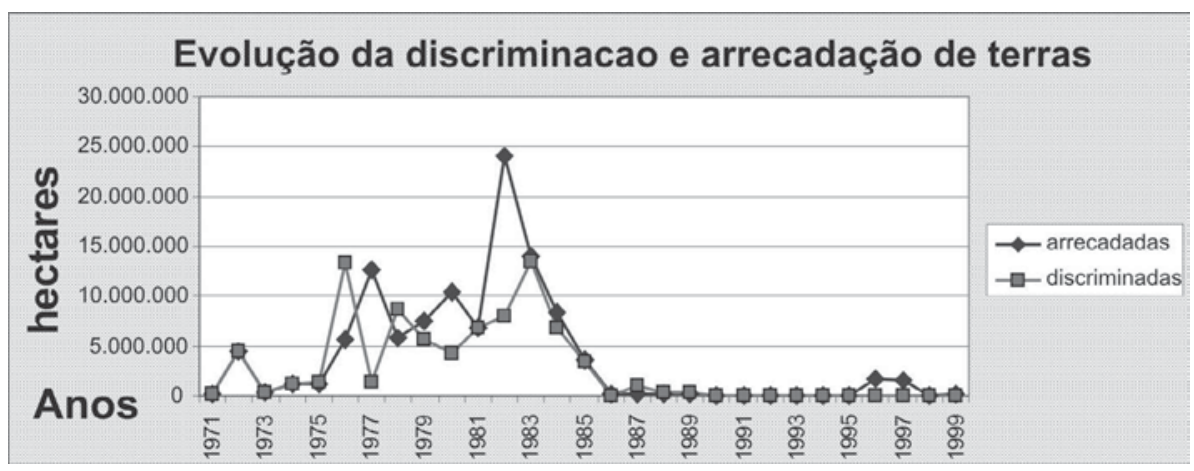

Fonte: Incra.

A Tabela 2 abaixo indica que, mesmo com o intenso trabalho desenvolvido recentemente, sem precedentes em qualquer outro período recente da política agrária brasileira, o volume de terras desapropriadas nos últimos quatro anos fica muito aquém do que se arrecadou com as ações discriminatórias. Outra implicação importante deste instrumento está na elaboração de um cadastro com informações de alta credibilidade que, somadas a outras informações sobre preços de mercado, pode gerar a base necessária para um efetivo imposto territorial.

Quadro 2 - Áreas Desapropriadas

\begin{tabular}{|cc|}
\hline Ano & Hectares \\
\hline $1985 / 89$ & 4.191 .147 \\
$1990 / 93$ & 2.775 .282 \\
$1993 / 94$ & 1.086 .546 \\
$1995 / 98$ & 7.321 .270 \\
\hline
\end{tabular}

\section{Conclusão}

Resumindo: abandonamos o instrumento de intervenção descentralizado, que fortalece os organismos locais de negociação do conflito fundiário, comprometendo as lideranças locais com sua execução; optamos por instrumentos de intervenção do governo federal, próximos do sistema de poder representado no Congresso, exatamente 
aquele que negociou arduamente o re-escalonamento da dívida do crédito rural.

Liberalização econômica combinada com federalização da política fundiária e de crédito rural, sem avanços significativos no nosso precário processo de representação política. Nada mais.

\section{Bibliografia}

Acemoglu, D.; Johnson, S. e Robinson, J. "Institutions as the Fundamental Cause of Long Run Growth”. NBER: Working Paper 10481, May 2004.

Aguirre, B. "Conflito e Cooperação; o caso da saúde pública no Brasil”, tese de livre-docência em elaboração, FEA/USP, 2006.

Hoff, K.; Braverman,A. e Stiglitz, J.E. “The Economics of Rural Organization”. The World Bank, Washington, 1993.

Silva, J. G., Grossi, M. e Porto, E.B.”(Re)negociações das Dívidas Agrícolas”. XLIV Congresso da Sociedade Brasileira de Economia e Sociologia Rural - SOBER, Grupo de Pesquisas: Políticas Setoriais e Macroeconômicas, Fortaleza, CE, 2006.

Dias, G."Estrutura Agrária e Crescimento Extensivo". USP-FEA, Tese de Livre-Docência: São Paulo,1978.

Dias, G.; Vieira, C.A. e Amaral, C.M."Comportamiento Del Mercado de Tierras em Brasil". Cap. VIII em "Mercado de Tierras Agrícolas em América Latina y el Caribe - una realidad incompleta”, Pedro Tejo compilador. Cepal; Santiago, 2003.

Cirne Lima, R."Pequena história territorial do Brasil: sesmarias e terras devolutas".Sulina: Porto Alegre, 1954.

Junqueira, M."O Instituto Brasileiro de Terras Devolutas”.Leal: São Paulo, 1976.

Mendonça Lima, R.A.”Direito Agrário”. Freitas Bastos: São Paulo,1977.

Navarro, Z."Sete teses equivocadas sobre as lutas sociais no campo, o MST e a reforma agrária”.UFRGS-Dept. de Sociologia: Porto Alegre, 1997. 
Dias, G. "Reforma Agrária: uma nota sobre o local de negociação", Revista de Estudos Avançados, Vol.11, N³1, pgs.111-116, Setembro-Dezembro, 1997.

Ribeiro, I.O.”Agricultura,democracia e socialismo”. Paz e Terra: Rio de Janeiro, 1987. 